\title{
An Investigation of the Effect of Different Nanofluids in a Solar Collector
}

\author{
Hamed Agabalaie Fakhim \\ Department of Mechanical Engineering, \\ Tabriz Branch, Islamic Azad University, \\ Tabriz, Iran \\ hamedfakhim@iaut.ac.ir
}

\begin{abstract}
In this article, we examine the use of different nanofluids in a solar collector in a parabolic form. Temperature, thermal efficiency and outlet average temperature for a conventional parabolic collector and a collector with nanofluid are compared. The effect of various parameters (concentration ratio, volume fraction of nanoparticles, absorption and fluid velocity) are studied. Results are discussed and it is shown that nano fluid increases the efficiency of the collector.
\end{abstract}

Keywords- nanofluid; water; solar collector; thermal efficiency; Numerical Analysis

\section{INTRODUCTION}

The importance of solar energy is widely recognized and is of increased significance for countries where favorable weather conditions permits increased exploitation through PVs and solar collectors [1-2]. However, the potential is often larger than the amounts of energy actually used. In Iran, the potential is calculated to be about 4,000 times its energy consumption [3]. Researchers have made different experiments and simulations to evaluate the performance of collectors. An experimental investigation can be in conjunction with the plate coverage [4]. The two-dimensional finite element method has been employed in order to investigate the collector's performance [5]. Another numerical simulation of the flat plate solar collector in which water has streamed showed good agreement with experimental results [6]. An effort to optimize a parabolic solar collector was conducted in [7] that included a comprehensive mathematical model of thermal and optical performance conditions of the collector. A considerable improvement in reducing radiation convection losses was reported [7]. The natural flow inside a waveform solar collector with the use of two nanofluids, using the finite element method, was investigated in [8]. It was concluded that the silver-water nanofluid had a better effect on increasing the heat transfer rate [8].

In this paper, the effect of nanofluids (water-silver and silver-copper) on the performance of a parabolic concentrator collector is examined. To improve the efficiency of the system, the nanoparticles are added to the fluid in the absorbing tube and as a result direct heat transfer is possible. This study numerically models the flow of nanofluid in the solar collector and describes its difference with a common collector.

\section{DESIGN OF SOLAR SYSTEMS}

Solar collectors work out as a heat exchangers in which a form of energy, solar energy, converts to another form of energy [9]. In general, it can be said that solar collectors absorb the solar radiation energy and convert it to heat. An essential part of the set up is anti-corrosion and the use of water and/or water with some additives such as antifreeze [10]. There are various different schemes that can be roughly categorized as active and passive, direct and indirect, full and back gravity systems. Passive systems include the use of very few moving and no electronic equipment. In these systems, storage and heat circulation are supplied with Thermosiphon or cold input water pressure. In active systems, electricity is used to supply the pump and the controllers. These systems are also known as mandatory rotation and have better management potential and performance on absorbed solar heat. Thermal, economic, environmental efficiency and lifetime of solar water heaters of Thermosiphon type have been examined in various works (e.g. [11]). An additional issue is the choice of solar collectors. Flat plate solar collectors are widely used due to their lower price, however vacuum tube collectors gain increased attention due to their improved characteristics.

\section{MODEL PARAMETERS}

Figure 1 shows the basic scheme of a solar collector, a water storage tank, heat exchangers and back tubes. Collector includes the absorber plate, glass coverage and side plates. Cube is with 1.2 length and $120 \mathrm{~mm}$ lateral distance. Height of absorbent to glass is $240 \mathrm{~mm}$ and insulator thickness under the absorbent is 30 millimeters. Pipe diameter inside the collector is $1.2 \mathrm{~mm}$ which passes from the adsorbent. Tubes on the parts outside the collector and the water tank are all assumed to be adiabatic. In the exact modeling, production of a precise computational grid is required for the geometric range. The control volume forms should be in a way to reduce computational error. The accuracy of the computational results in fluid dynamics depends heavily on the grids. Further, regular 
computing grids that include cubes controls volume increase the accuracy of the results and reduce the number of grids. The level of radiation in experiments has been obtained by averaging the amount of radiant energy on the top and bottom of the absorber tube. To evaluate the thermal performance of vacuum solar water heaters, a closed system instead of an open system is used.

The thermal performance of a vacuum tube solar water heater is obtained via (1)

$$
\eta=\frac{\dot{m} C_{p} \Delta T}{A_{c} G}
$$

In (1), $m$ represents the rate of mass flow of water heater inside the tank (via incoming and outgoing tank), $C_{p}$ represents the thermal capacity of the working fluid, $\Delta T$ represents the average increase in the temperature of the working fluid between the tank inlet and the outlet, $A_{c}$ represents the tube absorber level and $G$ represents the average solar radiation. For closed systems, the mass of the fluid inside the tank is used instead of m. 3D components related to the workspace are considered to only appear in the time of activity performance in simulation. Temporary activities were corresponding to the construction resources in three categories: materials, machinery or equipment and manpower. For each of the resources, an attributed space was designed that covered the main resource in the form of transparent and geometric volumes. The workspace of the construction resource was defined to produce the building components of one day and it is appeared daily and continuously besides building components and is hidden in the end of that day. Actually, after the construction of one day's workspace were hidden and then the corresponding volumes with 3D building components were appeared and remained to the end. In (2), $\Delta T$ represents the increase in the average temperature of the fluid inside tank, $\bar{G}$ represents the average solar radiation per tube and time represents the time of the experiment.

$$
\eta=\frac{m_{\tan k} C_{p} \Delta T}{\text { time, } \bar{G}}
$$

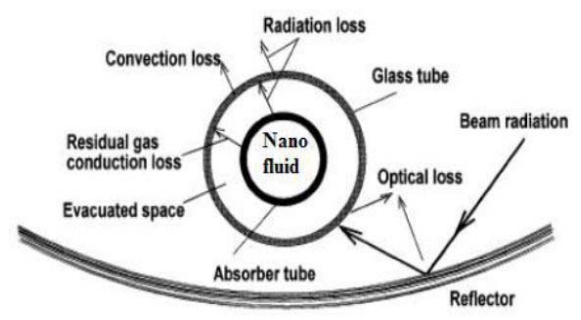

Fig. 1. Display of solar water heating system

\section{MATHEMATICAL Modeling}

To evaluate and analyze the theory of parabolic collector, the radiation source, nanofluids and concentrator have been numerically modeled. The spectral distribution of radiation by a black object is a function of wavelength and temperature which has been defined by the Planck distribution, in (3) [12].

$$
I_{b \lambda}\left(\lambda, T_{\text {sum }}\right)=\frac{2 h c_{0}^{2}}{\lambda\left[\exp \left(\frac{h c_{0}}{\lambda k_{B} T_{\text {sum }}}\right)-1\right]}
$$

In this equation, $T_{\text {sum }}$ represents the solar surface temperature, $h$ is Planck's constant, $k_{B}$ represents Boltzmann's constant, $c_{0}$ represents the speed of light in a vacuum and $\lambda$ the wavelength.

Spectral radiation intensity is calculated via (3). Energy emission wavelength is considered between $0.2-6 \mu \mathrm{m}$. In this research, the adsorbent is modeled as geometric and in form of a circular channel which has placed along linear parabolic concentrator. Water tank has been designed 10 liters regarding single-tube collector. To simplify the model, it is assumed that the absorber has a transmittance coefficient equaled to 1 . Nanofluid is modeled as a half-transparent environment, moving with constant speed. In this modeling, the radiation landing and then the energy transmission are considered through the absorption and Rayleigh scattering methods [13]. Received radiation in the water is due to absorption but received radiation caused by the interaction of nanoparticles is due to both scattering and absorption. The concentrator in Figure 1 converges the radiations caused by solar energy on adsorbent and a parameter called concentration ratio is defined to determine the convergence size [14]. For ease of severity, received radiation caused by solar energy is assumed in the radial direction. To receive and calculate radiation at various radiuses, the corrected form of Bayes equation in form of (4) is used.

$$
\frac{d\left(I_{\lambda} \cdot r\right)}{d r}=-\left(K_{a \lambda}+K_{s \lambda}\right) \cdot I_{\lambda} \cdot r=K_{e \lambda} \cdot I_{\lambda} \cdot r
$$

In (4), $K_{a \lambda}$ represents the absorption coefficient of the spectrum, $K_{s \lambda}$ represents the spectral scattering coefficient and $K_{e \lambda}$ represents the coefficient of received scattering. The tube inside collector has been made of copper with a thickness of one millimeter and a diameter of $1.27 \mathrm{~cm}$. It has been assumed that the inner surface of the collector is lined with black tubes to increase the absorption of radiation; tube as opaque surface has the absorption coefficient of 0.94 . The intensity of the radiation received in the nanofluid is caused by the effect of base fluid and nano-particles. When radiation passes through the water, received radiation takes place through absorption; received radiation takes place through scattering and absorbing incoming radiation in nanofluids. In the proposed model, the average diameter of the nanoparticles is about $8 \mathrm{~nm}$ thus the overall received coefficient is expressed in (5) via Riley equation.

$$
K_{e \lambda(\text { nanopartices })}=\frac{3 \phi Q_{e \lambda(\alpha, m)}}{2 D}
$$


In (5), $\phi$ represents the volume fraction of nanoparticles and $\mathrm{Q}_{\mathrm{e} \lambda}$ represents the received efficiency and $\mathrm{D}$ represents particle diameter. arepresents particle size and $\mathrm{m}$ represents the relative refractive index of particles obtained in (6) [7-15].

$$
\begin{gathered}
\alpha=\frac{\pi D}{\lambda} \\
m=\frac{m_{\text {particles }}}{n_{\text {fluid }}}
\end{gathered}
$$

Received efficiency in computing is obtained via (8).

$$
\begin{aligned}
& Q_{e \lambda}=4 \alpha I_{m}\left\{\frac{m^{2}-1}{m^{2}+1}\left[1+\frac{\alpha^{2}}{15}\left(\frac{m^{2}-1}{m^{2}+1}\right) \frac{m^{2}+27 m^{2}+38}{2 m^{2}+3}\right]\right\} \\
& +\left.\frac{8}{3} \alpha^{4}\left(\frac{m^{2}-1}{m^{2}+1}\right)\right|^{2}
\end{aligned}
$$

The ratio of the total received radiation for the nanofluid is obtained by the superposition of received base fluid and Nanofluid coefficient. Thus, in order to obtain the relationship between the radiation flows in the flow system, the placement of this amount in the Bayes equation is used. In the software, time-dependent equations in terms of both time and space are discrete. In (9), the amount of energy production $\left(E_{g n}\right)$ in the overall energy balance equation is expressed.

$$
\dot{E_{\text {in }}}-\dot{E}_{\text {out }}+\dot{E}_{\text {gen }}=\dot{E}_{\text {st }}
$$

In (9), $\dot{E}_{\text {in }}, \dot{E}_{\text {out }}, \dot{E}_{\text {gen }}, \dot{E}_{s t}$ represent the energy transmission to system, power transmission from system, power generation and energy storage respectively. To find the temperature field for the two-dimensional steady-state from the overall equation of equilibrium temperature, (9) is used. After obtaining the overall nanofluid temperature, average outlet temperatures, optical efficiency, thermal efficiency, etc. are calculated.

\section{A. Equations governing the flow}

To study and analyze the behavior of flows, the conservation of mass equations are used. For compressible flows or flows of heat transfer, energy conservation equations are solved. Under turbulent flow, turbulence modeling equations should be used.

The purpose of calculating flows, especially turbulent flows, is to determine the terms such as Reynolds stress, turbulent mass flux or turbulent heat flux by linking the mentioned amounts to the average flow quantities and especially existing gradients at average flow [9]. Mass conservation equation is written in (10).

$$
\frac{\partial \bar{\rho}}{\partial t}+\frac{\partial}{\partial x_{i}}\left(\overline{\rho u_{1}}\right)+\left(\rho^{\prime} u_{1}^{\prime}\right)=0
$$

by considering (10), the equation of momentum is written in (11).

$$
\rho \frac{D \bar{V}}{D t}+\rho \frac{\partial}{\partial x_{i}}\left(\rho \overline{u^{\prime} u_{j}^{\prime}}\right)=\rho g-\nabla \bar{P}+\mu \nabla^{2} V
$$

Energy equation is written in (12).

$$
\begin{aligned}
& \rho C_{p} \frac{D \bar{T}}{D t}=\frac{\partial}{\partial x_{i}}\left[-k \frac{\partial \bar{T}}{\partial x_{1}}+\rho C_{p} \overline{u_{1}^{\prime} T^{\prime}}\right] \\
& +\frac{\mu}{2}\left[\frac{\partial \overline{u_{1}}}{\partial x_{1}}+\frac{\partial u_{1}^{\prime}}{\partial x_{j}}+\frac{\partial \overline{u_{j}}}{\partial x_{1}}+\frac{\partial u_{j}^{\prime}}{\partial x_{1}}\right]
\end{aligned}
$$

\section{NUMERICAL SOLUTION}

To solve this set of equations, finite difference method is used, so that the total volume is decomposed to the initial controls volume with grids at their centre [10]. Absorbent with radius and length of $40 \mathrm{~mm}$ and $2.5 \mathrm{~mm}$ decomposes along radial direction. The size of the nodes along radial direction of axis $\mathrm{r}$ equals $0.5 \mathrm{~mm}$ and $1.2 \mathrm{~mm}$. The size of the grids is selected so that solutions are stable and convergent in iterations from simulation. Fluid temperature incoming the environment and the collector temperature are considered $25^{\circ} \mathrm{C}$. Further, convective heat transfer coefficient is equal to $6.75 \mathrm{~W} / \mathrm{m}^{2} \mathrm{~K}$. Incoming solar radiation flux to system is also considered be $1000 \mathrm{~W} / \mathrm{m}^{2} \mathrm{~K}$ [11]. In this calculation, the diameter of the nanoparticles and the volume fraction $(\phi)$ have been considered $8 \mathrm{~nm}$ and $0.03 \mathrm{wt} \%$, respectively. To obtain effective thermophysical properties of nanofluid, the rule of mixture is used [12].

$$
P_{\text {nanofluid }}=\phi P_{\text {particle }}+(1-\phi) P_{\text {basedfluid }}
$$

\section{STUDY ON RESULTS}

The results of two-dimensional field for collectors with Nanofluid and conventional collectors are displayed in Figure 2 and the comparison of the two collectors is shown in Table I. The results of the simulation in Table I show that the nanofluid collector outperforms the conventional collector under the same working conditions.

TABLE I. COMPARISON OF TWO COLLECTORS IN THE PROPOSED MODEL

\begin{tabular}{|c|c|c|c|}
\hline $\begin{array}{c}\text { Optical } \\
\text { efficiency } \\
(\%)\end{array}$ & $\begin{array}{c}\text { Thermal } \\
\text { efficiency } \\
\text { (\%) }\end{array}$ & $\begin{array}{c}\text { Average outlet } \\
\text { temperature (K) }\end{array}$ & Working fluid \\
\hline 322.5 & 27.8 & 33.2 & pure water \\
\hline 331.72 & 95.2 & 97.8 & Nanofluid \\
\hline
\end{tabular}

To optimize the proposed model, working parameters such as concentration ratio, volume fraction, the adsorbent and the flow rate were varied and their impact on the performance index is evaluated. The impact of nanofluid volume fraction (Ag/Water, $\mathrm{Al} /$ Water) on the temperature of the fluid in the tube is shown in Figures 3 and 4. As shown, the temperature 
difference will be about 2 degrees. If different percentage of nanoparticles is added to the base fluid, inlet and outlet temperature difference with respect to the used volume percent varies.

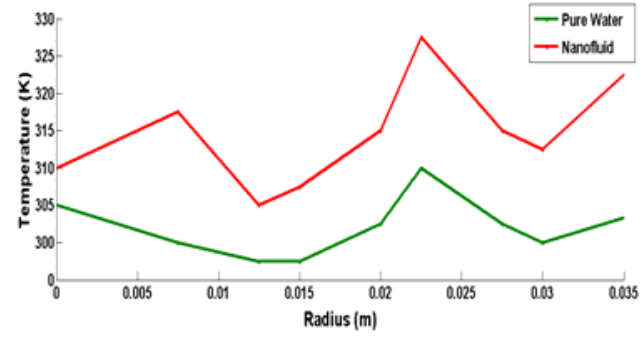

Fig. 2. Results from the two-dimensional field for collectors with nanofluid and conventional collectors

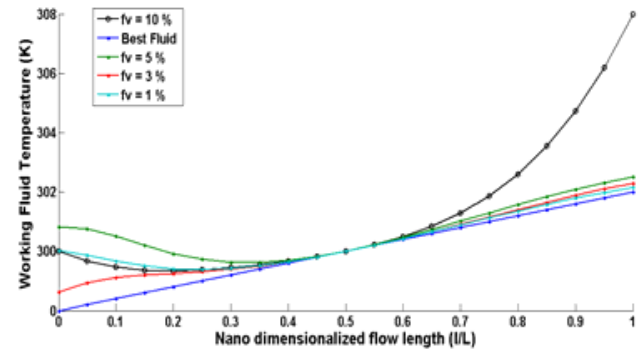

Fig. 3. The impact of the volume fraction of Nanofluids (Ag/Water) on the temperature of the fluid in the tube

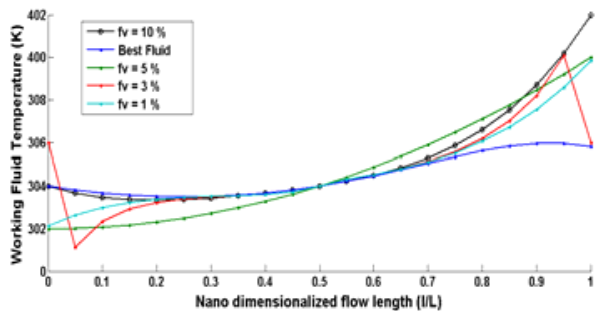

Fig. 4. The impact of the volume fraction of Nanofluids (A1/Water) on the temperature of the fluid in the tube

Considering Table I, it is specified that independent optical and thermal efficiency are the ratio of concentration, but the outlet temperature changes linearly with concentration ratio as shown in Figure 5. A change of the volume fraction has a significant impact on all three performance indicators. As shown in Figure 6, the average outlet temperature increases rapidly with increasing volume fraction to reach a certain speed and then it is almost constant. Indeed, there is a certain amount of volume fraction, after which certain progress does not occur in the average temperature outlet. Figure 7 shows the comparison of the temperature of the absorber plate and the working fluid along the tube using nanofluid with the same volume percentage. In case of using water as the fluid, the difference in the inlet and outlet temperature of water has the least temperature, and also the temperature difference between the beginning and end of the absorber plate has the highest amount, so that we will witness less efficiency using water as fluid. In case of nanofluid, there will be the highest difference on inlet and outlet temperature and lowest difference on the absorber plate. The Black lines display fluid temperature with nanoparticles and red lines display the temperature of the flowing water.

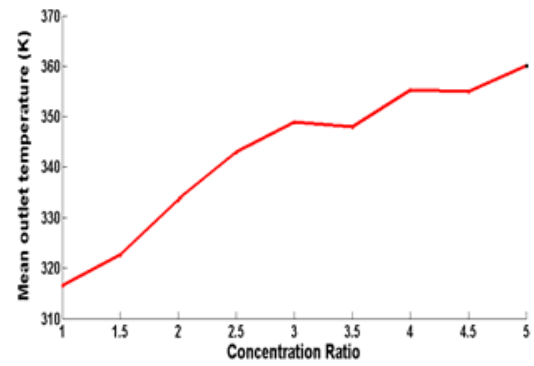

Fig. 5. Average outlet temperature of nanofluid based on collector concentration ratio

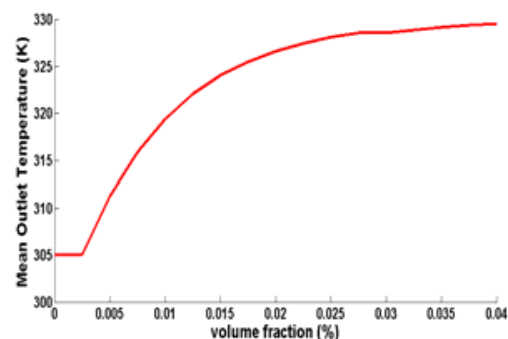

Fig. 6. Average outlet temperature in terms of volume fraction of nanoparticles

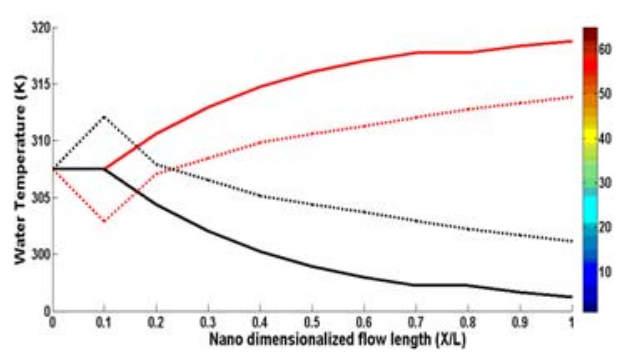

Fig. 7. Comparison of the temperature of the absorber plate and the working fluid along the tube

As shown in Figure 8, the average outlet temperature increases by increasing the absorber. This behavior is because of the fact that the duration at which a specific amount of working fluid passes absorber increases by constant flow speed and increased absorber, the fluid has more time to warm up along tube. On the contrary to Figure 8, thermal efficiency reduces by increasing the absorption. This increases due to increased absorber and thereby increased the time spent in the working fluid and heat loss increases through convection. On the other hand, by increasing the flow rate, the elapsed time in the adsorbent decreases, or in other words, less time is spent to increase temperature through radiation. Thus, with increasing speed, the average temperature of outlet reduces. By increasing the flow rate of heat loss, convection reduces and thermal efficiency increases (Figure 9). 


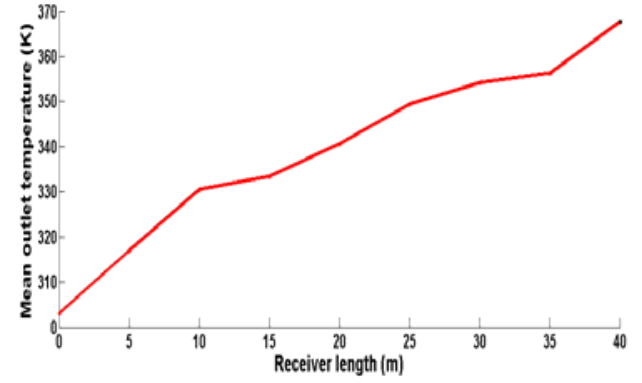

Fig. 8. Average outlet temperature in terms of absorber

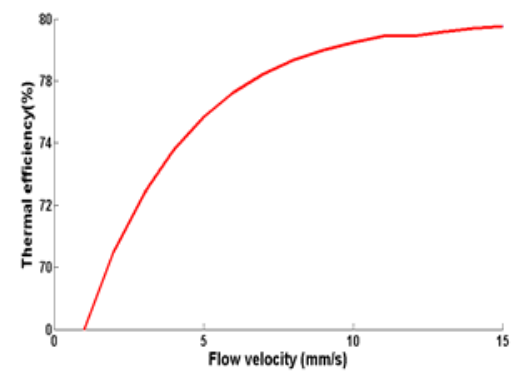

Fig. 9. Heat efficiency in terms of flow speed

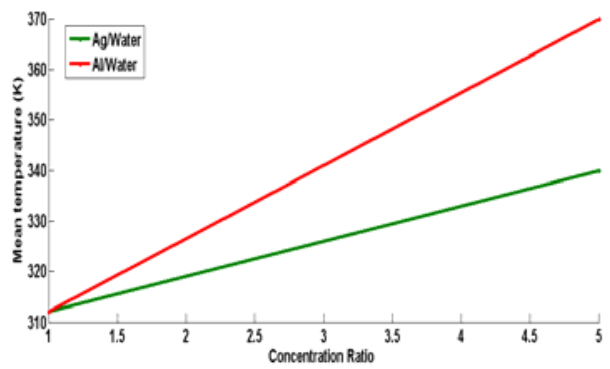

Fig. 10. Average outlet temperature in terms of collector concentration ratio.

\section{CONCLUSION}

In this research, the effect of different Nanofluids (Ag/Water, Al/Water) on a parabolic solar collector performance is discussed. The results of the simulations demonstrate that adding a small amount of nanoparticles, not only improves its absorption characteristics, but also improves the efficiency of the collector. An increase in the volume fraction will increase collector efficiency and fluid speed to a certain range. Further, by increasing the absorption, average outlet temperature increases but thermal efficiency decreases. On the contrary, this governs the speed increase so that the average temperature was reduced by increasing flow rate, but the heat efficiency increases. Overall, using nanofluids as the base fluid is shown to increase collector efficiency and outlet temperature.

\section{REFERENCES}

[1] A. W. Badar, R. Buchholz, F. Ziegler, "Experimental and theoretical evaluation of the overall heat loss coefficient of vacuum tubes of a solar collector", Solar Energy, Vol. 85, pp.1447-1456, 2011

[2] I. Budihardjo, G. L. Morrison, M. Behnia, "Natural circulation flow through water in glass evacuated tube solar collectors", Solar Energy, Vol. 81, pp. 1460-1472, 2007

[3] F. Jorge, O. Armando, "Numerical simulation of a trapezoidal cavity receiver for a linear Fresnel solar collector concentrator", Journal of Renewable Energy, Vol. 36, pp. 90-96, 2011

[4] K. Sopian, M. Syahri, S. Abdullah, M. Y. Othman, B. Yatim, "Performance of a non-metallic unglazed solar water heater with integrated storage system”, Renewable Energy, Vol. 29, pp.1421-1430, 2004

[5] R. S. R. Gorla, "Finite element analysis of a flat plate solar collector", Finite Elements in Analysis and Design, Vol. 24, pp. 283-290, 2010

[6] M. Selmi, M. J. Al-Khawaja, A. Marafia, "Validation of CFD simulation for flat plate solar energy collector", Renewable Energy, Vol. 33, pp. 383-387, 2008

[7] A. Kahrobaian, H. Malekmohammadi "Exergy Optimization Applied to Linear Parabolic Solar Collectors", Journal of Faculty of Engineering, Vol. 42, No. 1, pp. 131-144, 2008

[8] T. P. Otanicar, P. E. Phelan, R. S. Prasher, G. Rosengarten, R. A. Taylor, "Nanofluid-based direct absorption solar collector", Journal of Renewable and Sustainable Energy, Vol. 2, No. 3, p. 033102, 2010

[9] T. Yousefi, F. Veysi, E. Shojaeizadeh, S. Zinadini, "An experimental investigation on the effect of $\mathrm{pH}$ variation of MWCNT-H2O nanofluid on the efficiency of a flat-plate solar collector", Solar Energy, Vol. 86, No. 2, pp. 771-779, 2012

[10] M. F. Modest, Radiative Heat Transfer, Academic Press, 2003

[11] A. Kasaeian, A. Mohmmadkarim, A. Kaabinejadian, "Performance investigation of solar evacuated tube collector using TRNSYS in Tehran", International Journal of Renewable Energy Research, Vol. 4, No. 2, pp. 497-503, 2014

[12] F. P. Incropera, D. P. De Witt, Fundamentals of Heat and Mass Transfer, Wiley and Sons, New York, 2007

[13] H. Tyagi, P. Phelan, R. Prasher, "Predicted efficiency of a Lowtemperature Nanofluid-based direct absorption solar collector", ASME Journal of Solar Energy Engineering, Vol. 131, No. 4, pp. 04100410410047, 2009

[14] S. K. Das, S. U. Choi, W. Yu, T. Pradeep, Nanofluids: Science and Technology, Wiley and Sons, New York, 2008

[15] Z. Li, C. Chen, H. Luo, Y. Zhang, Y. Xue, "All-glass vacuum tube collector heat transfer model used in forced-circulation solar water heating system”, Solar Energy, Vol. 84, pp. 1413-1421, 2010 